PENELITIAN

\title{
PENGARUH TERAPI DISTRAKSI VISUAL DENGAN MEDIA VIRTUAL REALITY TERHADAP INTENSITAS NYERI PASIEN POST OPERASI LAPARATOMI
}

\author{
Rahmat Deri Yadi*, Ririn Sri Handayani*, Merah Bangsawan* \\ *Jurusan Keperawatan Poltekkes Tanjungkarang
}

\begin{abstract}
Nyeri post operasi laparotomi dapat dikelola dengan terapi farmakologi dan non farmakologi. Perawat memiliki peran yang sentral dalam upaya penurunan nyeri melalui berbagai modalitas keperawatan mandiri. Salah satunya adalah teknik distraksi visual dengan media virtual reality. Penelitian bertujuan untuk mengetahui pengaruh terapi distraksi visual dengan media virtual reality terhadap intensitas nyeri pada pasien post operasi laparatomi.Desain penelitian ini adalah pra eksperimen dengan rancangan one group pretest-posttest.Teknik sampling menggunakan teknik purposive sampling dengan jumlah sampel sebanyak 11 responden. Data nyeri dikumpulkan pre dan post tindakan, selanjutnya dianalisis secara univariat dan bivariat dengan uji Wilcoxon. Hasil penelitian diperoleh rata- rata intensitas nyeri sebelum terapi distraksi visual dengan media virtual reality 5.18 dengan standar deviasi 0.751 . Sedangkan intensitas nyeri sesudah terapi 3.55 dengan standar deviasi 1.036 . Hasil uji statistik didapatkan hasil $p$ value 0.002 ( $p$-value $0.002<\alpha 0.05$ ), maka disimpulkan ada pengaruh terapi distraksi visual dengan media virtual reality terhadap intensitas nyeri pada pasien post operasi laparatomi. Peneliti menyarankan agar terapi distraksi visual dengan media virtual reality digunakan sebagai salah satu intervensi mandiri keperawatan pada masalah nyeri pasien post operasi.
\end{abstract}

Kata kunci: distraksi visual, laparatomy, nyeri, virtual reality

\section{LATAR BELAKANG}

Pembedahan adalah suatu penanganan medis secara invasif yang di lakukan untuk mendiagnosis atau mengobati penyakit, injuri, atau deformitas tubuh (Nainggolan, 2013). Berdasarkan data yang diperoleh dari World Health Organization (WHO) dalam Tita (2017), jumlah pasien dengan tindakan operasi mencapai angka peningkatan yang sangat signifikan dari tahun ke tahun. Pada tahun 2011 terdapat 140 juta pasien di seluruh rumah sakit dunia, sedangkan pada tahun 2012 data mengalami peningkatan sebesar 148 juta jiwa. Di Indonesia, tindakan operasi pada tahun 2012 mencapai 1,2 juta jiwa. Tindakan operasi menempati urutan ke - 11 dari 50 pertama penanganan pola penyakit di rumah sakit se-Indonesia yang di perkirakan $32 \%$ diantaranya merupakan tindakan bedah laparatomi (Kemenkes RI, 2013 dalam Tita 2017).

Menurut World Health Organization (WHO), angka pembedahan laparatomi di Amerika Serikat disampaikan telah meningkat sebesar $50 \%$ dalam sepuluh tahun terakhir, yakni pada tahun 2006 sebesar 31,1\% antara tahun 2003 sampai 2010 terdapat peningkatan jumlah pembedahan laparatomi sebanyak $37,5 \%$ di seluruh negeri dari 16.000 sampai 60.000 (WHO, 2010). Departemen Kesehatan RI melaporkan bahwa peningkatan pembedahan laparatomi pada tahun 2005 sebanyak 162 dan menjadi 983 kasus pada tahun 2006 dan meningkat lagi pada tahun 2007 menjadi 1.281 kasus. (Windiarto, 2008). Berdasarkan survei yang dilakukan data yang di peroleh dari RSUD Dr. H. Abdul Moeloek Provinsi Lampung didapatkan jumlah pasien post operasi laparatomi pada bulan Oktober 2017 - Januari 2018 adalah 115 jiwa.

Pembedahan laparotomi, menurut Jitowiyono (2010) adalah pembedahan perut sampai membuka selaput perut.Laparatomi juga dilakukan pada kasus-kasus digestif dan kandungan, seperti apendiksitis, perforasi, hernia inguinalis, kanker lambung, kanker colon dan rectum, obstruksi usus, inflamasi usus 
kronis, kolestisitis dan peritonitis (Sjamsu Hidajat \& Jong, 2005).

Nyeri merupakan suatu rasa yang tidak nyaman, baik ringan maupun berat. Asosiasi internasional untuk penelitian nyeri (International Associatian for The Study of Paint, IASP, 1997) sebagaimana di kutip dalam Suzanne C. Smeltzer (2002) mendefinisikan nyeri sebagai suatu sensori subjektif dan pengalaman emosional yang tidak menyenangkan berkaitan dengan kerusakan jaringan yang aktual, potensial, atau yang dirasakan dalam kejadiaankejadian saat terjadi kerusakan.

Secara garis besar ada dua manajemen untuk mengatasi nyeri pasca operasi yaitu manajemen farmakologi dan manajemen non farmakologi. Teknik relaksasi dan distraksi merupakan salah satu metode manajemen nyeri non farmakologi.Salah satu tindakan pereda nyeri dengan menggunakan manajemen nonfarmakologi yaitu dengan terapi distraksi (Potter \& Perry, 2005) Menurut Kozier B. (2010). Distraksi terdiri dari beberapa teknik, salah satu nya adalah distrasi visual. Distraksi visual atau penglihatan adalah pengalihan perhatian selain nyeri yang diarahkan ke dalam tindakan-tindakan visual atau pengamatan.Dalam terapi distraksi visual ini peneliti menggunakan media tambahan yaitu dengan menggunakan media virtual reality.

Menurut Andre KP, (2010). Virtual Reality adalah teknologi yang membuat pengguna berinteraksi dengan suatu lingkungan yang disimulasikan oleh komputer (computer-simulatedenvironment). Teknologi virtual reality (VR) tak hanya digunakan untuk menikmati game. Teknologi ini dikembangkan untuk mengurangi rasa sakit dan kecemasan pasien.Peneliti Inggris ingin melihat apakah virtual reality (VR) mampu meringankan rasa sakit dan kecemasan pasien.Efek analgesik nonfarmakologi ini muncul saat pasien menggunakan virtual reality (VR) dengan simulasi lingkungan bersalju bersamaan dengan medikasi luka oleh dokter (Listiyani, 2017).
Penelitian Endah E. N dalam Nurhayanti, dkk. (2011) yang berjudul Pengaruh Teknik Distraksi Relaksasi Terhadap Penurunan Intensitas Nyeri Pada Pasien Post Operasi Laparatomi Di PKU Muhammadiyah Gombong sebanyak 43 responden didapatkan hasil p-value $=$ 0,000 . Oleh karena $p$ value $(0,000<0,05)$ maka H0 ditolak, artinya ada perbedaan antara pre dan post perlakuan teknik distraksi relaksasi terhadap penurunan intensitas nyeri post operasi laparatomi di RS PKU Muhammadiyah Gombong.

\section{METODE}

Jenis penelitian yang digunakan dalam penelitian ini adalah penelitian kuantitatif.Desain penelitian ini adalah penelitian dengan metode Pra-Eksperimen dengan menggunakan rancangan OneGroup Pretest-Posttest Design.Teknik sampling pada penelitian ini menggunakan teknik purposive sampling. Populasi dalam penelitian ini adalah seluruh pasien post operasi laparatomi yang mengalami nyeri.

Instrumen yang digunakan pada penelitian ini adalah lembar observasi dan lembar pengukuran skala nyeri menggunakan Numeric Rating Scale (NRS).Di tambah dengan alat dan bahan berupa handphone dan box virtual reality.

\section{HASIL}

Penelitian menggunakan 11 responden sebagaian besar berada pada usia 45-55 tahun (lansia awal) (54,5\%) dan sebagian besar berjenis kelamin laki-laki $(72,7 \%)$.

\section{Analisis Univariat}

Tabel 1: Distribusi Rata-rata Skala Nyeri Sebelum dan Sesudah Diberikan Terapi

\begin{tabular}{lcccc}
\hline Skala Nyeri & Mean & SD & Min-Max & $\mathrm{n}$ \\
\hline Sebelum & 5,18 & 0,751 & $4-6$ & \multirow{2}{*}{11} \\
\cline { 1 - 4 } Sesudah & 3,55 & 1,036 & $2-5$ & \\
\hline
\end{tabular}


Berdasarkan tabel di atas didapatkan bahwa hasil pengukuran rata-rata skala nyeri pada pasien post operasi laparatomi sebelum diberikan terapi distraksi visual dengan media virtual reality adalah mean 5,18 , dengan standar deviasi 0,751 , nilai nyeri terendah adalah 4 dan nilai nyeri tertinggi adalah 6. Pengukuran rata-rata nyeri pada pasien post operasi laparatomi sesudah diberikan terapi distraksi visual dengan media virtual reality adalah mean 3,55 , dengan standar deviasi 1,036 , nilai nyeri terendah adalah 2 dan nilai nyeri tertinggi adalah 5 .

\section{Analisis Bivariat}

Tabel 2: Distribusi Analisis Perbedaan Rata-rata Skala Nyeri Sebelum dan Sesudah Terapi

\begin{tabular}{lcccc}
\hline Skala Nyeri & Mean & SD & p value & $\mathrm{n}$ \\
\hline Sebelum & 5,18 & 0,751 & \multirow{2}{*}{0,002} & 11 \\
\hline Sesudah & 3,55 & 1,036 & & \\
\hline
\end{tabular}

Berdasarkan tabel di atas dapat disimpulkan bahwa distribusi rata-rata nyeri post operasi sebelum diberikan terapi distraksi visual dengan media virtual reality adalah 5,18. Pada pengukuran distribusi rata-rata nyeri setelah diberikan terapi distraksi visual dengan media virtual reality didapatkan rata-rata nyeri post operasi adalah 3,55. Nilai perbedaan mean antara nyeri sebelum dan sesudah diberikan terapi distraksi visual dengan media virtual reality adalah 1,63.

Hasil ststistik dengan uji wilcoxon didapatkan hasil $p$ value sebesar $(0,002)<\alpha$ $(0,05)$, hal ini menunjukkan Ha diterima yang artinya terapi distraksi visual dengan media virtual reality memiliki pengaruh dalam menurunkan tingkat nyeri pada pasien post operasi laparatomi.

\section{PEMBAHASAN}

Hasil penelitian menunjukkan adanya perbedaan skala nyeri sebelum dan sesudah diberikan terapi distraksi visual dengan media virtual reality. Sehingga dapat disimpulkan bahwa ada pengaruh terapi distraksi visual dengan media virtual reality terhadap intensitas nyeri pada pasien post operasi laparatomi.

Hal ini sejalan dengan penelitian Endah E. N dalam Nurhayanti, dkk. (2011) yang berjudul pengaruh teknik distraksi relaksasi terhadap penurunan intensitas nyeri pada pasien post operasi laparatomi di PKU Muhammadiyah Gombong sebanyak 43 responden didapatkan hasil $p$ value $=0,000$. Oleh karena $p$ value $(0,000$ $<0,05)$ maka Ho ditolak, artinya ada perbedaan antara pre dan post perlakuan teknik distraksi relaksasi terhadap penurunan intensitas nyeri post operasi laparatomi di RS PKU Muhammadiyah Gombong.

Nyeri merupakan suatu sensori subjektif dan pengalaman emosional yang tidak menyenangkan berkaitan dengan kerusakan jaringan yang aktual, potensial, atau yang dirasakan dalam kejadiaankejadian saat terjadi kerusakan. (Smeltzer \& Bare, 2002).Usia mempunyai peranan yang penting dalam mempersepsikan dan mengekspresi kan rasa nyeri. Makin bertambahnya usia seseorang makin bertambah pula pemahaman terhadap nyeri dan usaha untuk mengatasinya (Tamsuri 2007).

Penanganan nyeri ada 2 yaitu dengan teknik farmakologi dan non farmakologi. Intervensi farmakologis antara lain (analgetik : non narkotik dan obat anti inflamasi nonsteroid (NSAID), analgetik narkotik atau otopiat, dan obat tambahan adjuvant). Intervensi non farmakologi salah satunya adalah terapi distraksi (Potter \& Perry, 2005).

Menurut Kozier B. (2010). Distraksi terdiri dari beberapa teknik salah satu nya adalah distraksi visual. Distraksi visual atau penglihatan adalah pengalihan perhatian selain nyeri yang diarahkan ke dalam tindakan-tindakan visual atau pengamatan.Tujuan dari penggunaan teknik distraksi visual ini adalah untuk pengalihan atau menjauhi perhatian terhadap sesuatu yang sedang dihadapi, misalnya rasa sakit (nyeri). 
Menurut peneliti pasien yang telah menjalanin operasi laparatomi akan merasakan nyeri hal ini dikarenakan tindakan yang dilakukan adalah dengan cara membedah atau menyayat lapisan perut lapis demi lapis sehingga menyebabkan nyeri yang dirasakan oleh pasien post operasi. Menurut peneliti terapi distraksi visual dengan media virtual reality dapat diberikan kepada pasien post operasi untuk menurunkan skala nyeri.Jika dilihat dari analisa bivariat dapat disimpulkan terdapat pengaruh terapi distraksi visual dengan media virtual reality terhadap intensitas nyeri pada pasien post opersi laparatomi.

\section{KESIMPULAN}

Hasil penelitian menyimpulkan bahwa rata-rata skala nyeri responden menurun setalah diberikanterapi distraksi visual dengan media virtual reality dari skala 5,18 menjadi 3,55. Hasil analisis lebih lanjut menunjukan adanya perbedaan penurunan rata-rata skala nyeri sebelum diberikan terapi distraksi visual dengan media virtual realitypada pasien post operasi laparatomi dengan $p$ value $0,002(p$ value <0,05).

Hasil tersebut merekomendasikan kepada rumah sakit agar dapat memfasilitasi sarana dan prasarana yang diperlukan untuk terapi distraksi visual sebagai salah satu terapi nonfarmakologi untuk mangatasi masalah nyeri. Selanjutnya bagi perawat diharapkan mau dan mampu untuk memberikan terapi distraksi visual dengan media virtual reality pada pasien dengan masalah nyeri khususnya pada pasien post operasi laparotomi.

\section{DAFTAR PUSTAKA}

Andre K.P. (2010). Mudah Membuat Game Augmented Reality (AR) dan Virtual Reality (VR) dengan Unity $3 D$. Jakarta: Elex Media.

Jitowiyono, S. (2010). Asuhan Keperawatan Post Operatif. Yogya karta: Nuha Medika.

Kozier, B. (2010). Buku Ajar Fundamental Keperawatan : konsep, proses, dan praktik. Jakarta: EGC.

Kozier, e. (2010). Buku Ajar Keperawatan Fundamental : Konsep, Proses, dan Praktik. Ed,7. Vol.1. Jakarta: EGC.

Listiyani, D. (2017). Peneliti Gunakan Virtual Reality (VR) untuk Kurangi Rasa Sakit Pasien.diperoleh dari https://techno.okezone.com/read/201 7/06/15/207/1717236/penelitigunakan-vr-pasien pada tanggal 18 mei 2018.

Nurhayanti, d. (2011). Pengaruh Teknik Distraksi Relaksasi Terhadap Penurun an Intensitas Nyeri Pada Pasien Post Operasi Laparatomi Di PKU Muhammadiyah Gombong. diperoleh

https://ejournal.stikesmuhgombong.a c.id/index.php/JIKK/article/view/23/ 22 pada tanggal 9 maret 2018.

Perry \& Potter. (2005). Buku Ajar Fndamental Keperawatan : Konsep, Proses, dan Praktik, Vol 2. Edisi 4. Jakarta: EGC.

Smelzert, S. (2010). Buku Ajar Keperawat an Medikal Bedah (Terjemahan) Edisi 8.Volume 1. Jakarta: EGC.

Tita, N. P. (2017). Faktor-Faktor yang Berhubungan dengan Kejadian Wound Dehiscence pada Pasien Post Laparatomy. diperoleh dari http://jkp.fkep.unpad.ac.id/index.php /jkp/article/view/455/165pada tanggal 26 februari 2018. 